\title{
Vascular Inflammation in Lungs of Patients with Fatal Coronavirus Disease 2019 (COVID-19): Possible Role for the NLRP3 Inflammasome
}

\author{
Oindrila Paul \\ University of Pennsylvania Perelman School of Medicine \\ Jian Qin Tao \\ University of Pennsylvania Perelman School of Medicine \\ Eric West \\ University of Pennsylvania Perelman School of Medicine \\ Leslie Litzky \\ University of Pennsylvania Perelman School of Medicine \\ Michael Feldman \\ University of Pennsylvania Perelman School of Medicine \\ Kathleen Montone \\ University of Pennsylvania Perelman School of Medicine \\ Chamith Rajapakse \\ University of Pennsylvania Perelman School of Medicine \\ Christian Bermudez \\ University of Pennsylvania Perelman School of Medicine \\ Shampa Chatterjee ( $\nabla$ shampac@pennmedicine.upenn.edu ) \\ Penn: University of Pennsylvania
}

\section{Research Article}

Keywords: Hyperinflammation, SARS-CoV-2, acute respiratory disease syndrome (ARDS), fatal COVID-19, NLRP3

Posted Date: September 1st, 2021

DOI: https://doi.org/10.21203/rs.3.rs-842167/v1

License: (c) (i) This work is licensed under a Creative Commons Attribution 4.0 International License. Read Full License 


\section{Abstract}

Background: Hyperinflammation is a key event that occurs with SARS-CoV-2 infection. In the lung, hyperinflammation leads to structural damage to tissue. To date, numerous lung histological studies have shown extensive alveolar damage, but there is scarce documentation of vascular inflammation in postmortem lung tissue.

Methods: Lung sections from 8 COVID-19 affected and 11 non-COVID-19 subjects [of which 8 were acute respiratory disease syndrome (ARDS) affected and 3 were from subjects with non-respiratory diseases] were stained for $\mathrm{H}$ \& $\mathrm{E}$ to ascertain histopathological features including presence of thrombi/microthrombi. Inflammation along the vessel wall was also monitored by quantification of the expression of moieties of the NLRP3 inflammasome pathway (NLRP3 and caspase-1).

Results: In lungs from "fatal COVID-19", vascular changes in the form of microthrombi in small vessels, arterial thrombosis, and organization were extensive as compared to lungs from "non-COVID-19 non respiratory disease" affected subjects. The NLRP3 pathway components were significantly higher in lungs from COVID-19 subjects as compared to non-COVID-19 fatal cases without respiratory disease. No significant differences were observed between COVID-19 lungs and non-COVID-19 ARDS lungs.

Conclusion: We posit that inflammasome formation along the vessel wall is a characteristic of lung inflammation that accompanies COVID-19. Thus, the NLRP3 inflammasome pathway seems to be probable candidate that drives amplification of inflammation post SARS-CoV-2 infection.

\section{Introduction}

It has been more than a year since the pandemic caused by the novel SARS-CoV-2 corona virus (Severe Acute Respiratory Syndrome Coronavirus), also known as COVID-19 has affected large populations globally [1, 2]. The virus disproportionately affects the respiratory system and a major cause of fatality is the acute respiratory distress syndrome (ARDS) that accompanies the infection $[3,4]$. Autopsy-based lung histological studies have been an invaluable tool in understanding the pathobiology of COVID-19; indeed these have shown indications of inflammation, edema, coagulopathy and fibrosis [3,5-8]. COVID-19 manifests itself under a wide spectrum of symptoms, but it can broadly be classified as an inflammatory disease where excessive inflammation is the main driver of poor clinical outcome $[9,10]$. In this direction, the vascular endothelium, a dynamically adaptable interface that is actively involved in recruitment of inflammatory cells, possibly plays a crucial role in regulation, progression, and amplification of inflammation. While post mortem findings have shown alveolar damage, early or intermediate proliferative phase, and presence of thrombi and signs of inflammation in the lungs $[3,6,8]$, histopathology in the context of vascular inflammation and altered vascular structures has been somewhat scarce $[7,11]$.

Inflammatory processes involve the participation of inflammasomes that are multimeric platforms assembled in response to pathogenic stimuli. Dysregulated inflammasome signaling has been well established as a pivotal event in hyper-inflammatory syndromes [12-14]. Among the inflammasomes, the NLRP3 inflammasome comprising of the NLRP3 subunit, ASC and caspase-1, is well established to be activated in response to microbial infection $[15,16]$ and to drive cell death $[17,18]$. It is also involved in COVID-19, as evidenced by the detection of inflammasome subunits and products in the sera and lung tissue of COVID-19 patients $[19,20]$. However, there are no reports of the presence of the inflammasome in the pulmonary vasculature with COVID-19 infection. As the vasculature seems to be crucial in inflammation accompanying COVID-19, the status of NLRP3 along the vascular wall needs to be documented.

We posit that inflammasome formation is characteristic of pulmonary vascular inflammation that accompanies COVID-19. The purpose of this study is to contextualize vascular features in lung tissue in fatal cases of COVID-19 as compared to other pulmonary diseases and ascertain NLRP3 expression along the vascular wall. Here we document the major histological findings of 8 postmortem examinations done on patients with clinically confirmed COVID-19 and compare these to lungs of non-COVID19 subjects. This study contributes to the growing data on this topic $[3,6,21-24]$.

\section{Materials And Methods}


We analyzed lung tissue samples of 8 patients that died of COVID-19 in 2020 and 11 patients that died from non-COVID complications. Written informed consent was obtained for postmortem examination from the next of kin of these patients. For the COVID-19 patients, SARS-CoV-2 infection was confirmed by real time PCR analysis at the time of hospital admission. Autopsies were done by trained personnel using personal protective equipment in accordance with the recommendations of the University of Pennsylvania School Of Medicine.

Tissue blocks taken from the most representative areas of the lung (as identified by macroscopic examination) were fixed in formalin. Paraffin embedded sections of 3 to $5 \mu \mathrm{m}$ thickness were stained with hematoxylin and eosin (H \& E). Images were captured on the Aperio Pathology System and visualized by ImageScope (Leica Biosystems, Buffalo Grove, IL). High and low powered fields were selected for evaluation. Inflammation and inflammation induced cell death (pyroptosis) were characterized by immunostaining for NLRP3 inflammasome and caspase-1 respectively. Sections were deparaffinized; after antibody retrieval, were stained using anti-human NLRP3 monoclonal antibody at 1:200 or anti-human caspase antibody at 1:100 (both from R\&D Systems, Minneapolis, MN). Secondary antibody used was conjugated to Alexa 488 at 1:200 (Life Technologies, Eugene, OR).

Appropriate IgG controls were used to fix exposure settings. Vectashield antifade mounting medium used was from Vector Labs (Burlingame, CA). Images were acquired by epifluorescence microscopy using a Nikon TMD epifluorescence microscope, equipped a Hamamatsu ORCA-100 digital camera, and MetaMorph imaging software (Universal Imaging, West Chester, PA, USA). Fluorescence images were acquired at excitation $=488 \mathrm{~nm}$; all images were acquired with the same exposure and acquisition settings as reported previously [25-27]. Quantitation of the fluorescence signal was carried out using the MetaMorph Imaging Software. Integrated Intensities were normalized to the field area as reported by us elsewhere ${ }^{40}$.

\section{Results}

Patient demographics and clinical information are summarized in Tables 1 and 2, histological characteristics in Tables 3 and 4. COVID-19 patients were 4 men and 4 women, with a mean age of 71.8 years (SD 13.9); non-COVID-19 patients were 7 men and 4 women, with a mean age of 64 (SD 10.7). Lung sections from all patients showed diffuse alveolar damage including hyaline membranes, intra-alveolar fibrin deposition, and thickening of the alveolar-capillary membrane. All sections from lungs also stained positively for the NLRP3 inflammasome associated markers that were assessed and quantitated by fluorescence imaging. 
Table 1

Patient characteristics, comorbidities, select immunostaining findings on a score of 0 to 3 : 0 , absent; 1 , mild; 2 , moderate; 3 , severe.

\begin{tabular}{|c|c|c|c|c|c|c|c|}
\hline Patient & Gender & Age & $\begin{array}{l}\text { Known Medical } \\
\text { History }\end{array}$ & $\begin{array}{l}\text { Substance Abuse } \\
\text { (Smoking/Alcohol) }\end{array}$ & Thrombi/microthombi & $\begin{array}{l}\text { NLRP3 } \\
\text { expression }\end{array}$ & $\begin{array}{l}\text { NLRP3 } \\
\text { activation } \\
\text { (caspase- } \\
\text { 1) }\end{array}$ \\
\hline 1. & Female & 61 & Asthma and Stroke & Non-smoking & 2 & 2 & 3 \\
\hline 2. & Female & 63 & $\begin{array}{l}\text { Breast cancer and } \\
\text { therapy related } \\
\text { Acute Leukemia }\end{array}$ & Smoking & 3 & 2 & 3 \\
\hline 3. & Female & 73 & COPD & $\begin{array}{l}\text { Smoking and } \\
\text { Alcohol }\end{array}$ & 3 & 2 & 3 \\
\hline 4. & Female & 94 & $\begin{array}{l}\text { COPD, Coronary } \\
\text { Artery Disease and } \\
\text { Sjogrens disease }\end{array}$ & Not known & 3 & 2 & 3 \\
\hline 5. & Male & 50 & $\begin{array}{l}\text { Myeloproliferative } \\
\text { disorder and } \\
\text { Pulmonary/portal } \\
\text { Hypertension }\end{array}$ & Not known & 3 & 2 & 3 \\
\hline 6. & Male & 72 & $\begin{array}{l}\text { Dementia, Diabetes } \\
\text { and Hypertension }\end{array}$ & Not known & 3 & 3 & 3 \\
\hline 7. & Male & 77 & $\begin{array}{l}\text { Pulmonary } \\
\text { Embolism and } \\
\text { Deep Vein } \\
\text { Thrombosis and } \\
\text { Hypertension }\end{array}$ & Not known & 3 & 3 & 3 \\
\hline 8. & Male & 85 & $\begin{array}{l}\text { Cerebral Vascular } \\
\text { Disease }\end{array}$ & Not known & 3 & 2 & 3 \\
\hline
\end{tabular}


Table 2

Patient characteristics, comorbidities, select immunostaining findings for non-COVID-19 lungs on a score of 0 to 3: 0 , absent; 1 , mild; 2 , moderate; 3 , severe.

\begin{tabular}{|c|c|c|c|c|c|c|c|}
\hline Patient & Gender & Age & $\begin{array}{l}\text { Known Medical } \\
\text { History }\end{array}$ & $\begin{array}{l}\text { Substance Abuse } \\
\text { (Smoking/Alcohol) }\end{array}$ & Thrombi/microthombi & $\begin{array}{l}\text { NLRP3 } \\
\text { expression }\end{array}$ & $\begin{array}{l}\text { NLRP3 } \\
\text { activation } \\
\text { (caspase- } \\
\text { 1) }\end{array}$ \\
\hline $1 \mathrm{nc}$. & Male & $60 s$ & Heart Transplant & Not Known & 1 & 2 & 1 \\
\hline 2 nc. & Female & $50 \mathrm{~s}$ & Emphysema & Not Known & 1 & 3 & 2 \\
\hline $3 \mathrm{nc}$. & Male & $80 \mathrm{~s}$ & Emphysema & Not Known & 1 & 3 & 3 \\
\hline $4 \mathrm{nc}$. & Male & $40 \mathrm{~s}$ & Bronchopneumonia & Not Known & 2 & 3 & 3 \\
\hline $5 \mathrm{nc}$. & Female & $60 s$ & $\begin{array}{l}\text { Diffuse alveolar } \\
\text { damage; chronic } \\
\text { lung disease }\end{array}$ & Not Known & 1 & 2 & 2 \\
\hline $6 \mathrm{nc}$. & Male & $70 \mathrm{~s}$ & $\begin{array}{l}\text { End stage lung } \\
\text { disease }\end{array}$ & Not Known & 1 & 2 & 3 \\
\hline $7 \mathrm{nc}$. & Female & $60 s$ & $\begin{array}{l}\text { Diffuse alveolar } \\
\text { damage; COPD and } \\
\text { renal cell } \\
\text { carcinoma }\end{array}$ & Not Known & 2 & 3 & 3 \\
\hline $8 \mathrm{nc}$. & Female & $50 s$ & Mild edema in lung & Not Known & 1 & 1 & 1 \\
\hline 9 nc. & Male & $70 \mathrm{~s}$ & COPD & Not Known & 1 & 3 & 3 \\
\hline 10nc. & Male & $70 \mathrm{~s}$ & $\begin{array}{l}\text { Aspiration } \\
\text { pneumonia; } \\
\text { diabetes }\end{array}$ & Not Known & 2 & 2 & 2 \\
\hline $11 \mathrm{nc}$. & Male & $50 \mathrm{~s}$ & Sarcoid & Not Known & 1 & 1 & 1 \\
\hline
\end{tabular}

Table 3

Pulmonary pathological features in COVID-19 autopsy cases on a score of 0 to 4: 0 , absent; 1 , mild 2, moderate; 3 , high; 4, severe.

\begin{tabular}{|c|c|c|c|c|c|}
\hline $\begin{array}{l}\text { Patient } \\
\text { No. }\end{array}$ & $\begin{array}{l}\text { Hyaline } \\
\text { Membranes }\end{array}$ & $\begin{array}{l}\text { Interstitial } \\
\text { Fibrosis }\end{array}$ & $\begin{array}{l}\text { Atypical } \\
\text { pneumocytes }\end{array}$ & $\begin{array}{l}\text { Pulmonary } \\
\text { hemorrhage }\end{array}$ & Morphological aspects \\
\hline 1. & 4 & 4 & 4 & 3 & $\begin{array}{l}\text { Proliferative phase of diffuse alveolar damage, } \\
\text { thrombi/microthrombi. }\end{array}$ \\
\hline 2. & 3 & 3 & 4 & 3 & $\begin{array}{l}\text { Emphysematous change, microthrombi, alveolar } \\
\text { septal thickening, thrombi/microthrombi. }\end{array}$ \\
\hline 3. & 4 & 4 & 4 & 3 & Pulmonary edema, alveolar septal thickening \\
\hline 4. & 4 & 4 & 4 & 4 & $\begin{array}{l}\text { Proliferative phase of diffuse alveolar damage, } \\
\text { pulmonary hemorrhage, thrombi/microthrombi. }\end{array}$ \\
\hline 5. & 4 & 4 & 4 & 3 & $\begin{array}{l}\text { Diffuse alveolar damage, Advanced proliferative } \\
\text { phase, thrombi/microthrombi. }\end{array}$ \\
\hline 6. & 4 & 4 & 4 & 4 & $\begin{array}{l}\text { Advanced proliferative phase, pulmonary } \\
\text { hemorrhage, thrombi/microthrombi. }\end{array}$ \\
\hline 7. & 4 & 4 & 4 & 4 & $\begin{array}{l}\text { Exudative phase diffuse alveolar damage, } \\
\text { hemorrhage, thrombi/microthrombi. }\end{array}$ \\
\hline 8. & 4 & 4 & 4 & 4 & $\begin{array}{l}\text { Advanced proliferative phase, hemorrhage, } \\
\text { thrombi/microthrombi. }\end{array}$ \\
\hline
\end{tabular}


Table 4

Pulmonary pathological features in non-COVID-19 (nc) autopsy cases on a score of 0 to 4: 0 , absent; 1 , mild 2, moderate; 3 , high; 4, severe.

\begin{tabular}{|c|c|c|c|c|c|}
\hline & $\begin{array}{l}\text { Hyaline } \\
\text { Membranes }\end{array}$ & $\begin{array}{l}\text { Interstitial } \\
\text { Fibrosis }\end{array}$ & $\begin{array}{l}\text { Atypical } \\
\text { pneumocytes }\end{array}$ & $\begin{array}{l}\text { Pulmonary } \\
\text { hemorrhage }\end{array}$ & Morphological aspects \\
\hline $\begin{array}{l}1 \\
\text { nc. }\end{array}$ & 2 & 3 & 2 & 2 & Fibrotic pattern, hyaline membranes, \\
\hline $\begin{array}{l}2 \\
\text { nc. }\end{array}$ & 3 & 3 & 4 & 3 & Intracapillary hyaline thrombi \\
\hline $\begin{array}{l}3 \\
\mathrm{nc}\end{array}$ & 4 & 4 & 4 & 1 & Fibrosis, hyperplasia, proteinaceous exudate in alveoli. \\
\hline $\begin{array}{l}4 \\
\mathrm{nc}\end{array}$ & 4 & 4 & 4 & 3 & $\begin{array}{l}\text { Acute fibrinous and organizing pneumonia, } \\
\text { Microthrombi, hyaline membranes }\end{array}$ \\
\hline $\begin{array}{l}5 \\
\mathrm{nc}\end{array}$ & 4 & 4 & 4 & 4 & $\begin{array}{l}\text { intra-alveolar edema, hemorrhage, capillary } \\
\text { congestion, proteinaceous hyaline membrane }\end{array}$ \\
\hline $\begin{array}{l}6 \\
\mathrm{nc}\end{array}$ & 4 & 4 & 4 & 3 & $\begin{array}{l}\text { Observed vascular changes in the form of diffuse } \\
\text { (micro)vascular damage } \\
\text { with large thrombi }\end{array}$ \\
\hline $\begin{array}{l}7 \\
\text { nc }\end{array}$ & 4 & 4 & 4 & 2 & $\begin{array}{l}\text { Proteinaceous exudate in alveolar space, hyaline } \\
\text { membranes. }\end{array}$ \\
\hline $\begin{array}{l}8 \\
\mathrm{nc}\end{array}$ & 1 & 1 & 1 & 1 & Mild alveolar distention \\
\hline $\begin{array}{l}9 \\
\mathrm{nc}\end{array}$ & 3 & 2 & 2 & 3 & $\begin{array}{l}\text { Extensive presence of fibrin within the alveolar spaces, } \\
\text { proteinaceous exudate }\end{array}$ \\
\hline $\begin{array}{l}10 \\
\mathrm{nc}\end{array}$ & 4 & 4 & 4 & 4 & Exudative phase of diffuse alveolar damage \\
\hline $\begin{array}{l}11 \\
\text { nc }\end{array}$ & 2 & 2 & 2 & 1 & Presence of hyaline membranes, fibrin aggregates \\
\hline
\end{tabular}

Upon light microscopic examination, the lungs of all COVID-19 patients showed extensive alteration of lung microstructure (Fig. 1A, B). A closer inspection of COVID-19 lungs revealed fibrin exudation into alveolar space, extensive thrombi and fibroblastic proliferation, hyaline membrane, fibrin deposition and early and advanced proliferative phase of diffuse alveolar damage (Fig. 1B). Thrombi and microthrombi were identified in 7 of the 8 patients (Fig. 1C). Vascular changes were extensive, with microthrombi in small vessels and arterial thrombosis and organization. Microthrombi were also observed in alveolar septa. Thrombi and microthrombi were found in $>75-80 \%$ of the fields imaged. Histological findings are detailed in the legends of Fig. 1 and in Table 2.

In contrast, the lungs from non-COVID fatal cases, showed less thrombi and fibrin exudation (Fig. 2A, B). While higher magnification showed certain key features of lung injury such as diffuse alveolar damage, thickening of the alveolar-capillary membrane, fibroblastic proliferation, the presence of hyaline membranes, edema and proliferative phase of diffuse alveolar damage, the non-ARDS lungs (nc 1, 8 and 11) have intact structure and did not show alveolar infiltration or hemorrhage (Fig. 2B). Furthermore, in non-COVID-19 lungs, vessels showed thrombus in about $<40 \%$ of the fields (Fig. 2C).

We next assessed the expression of the NLRP3 subunit and its downstream effector caspase-1 in all samples. In lungs from COVID-19 subjects, intense expression of the NLRP3 and caspase-1 as observed from the green-fluorescent signal, is shown in Fig. 3. Fluorescence around the vessel walls implied NLRP3 expression along the endothelial layer (Fig. 3A, upper panels). The effector enzyme, caspase-1 was widely distributed throughout the lungs and was not limited to the vascular structures (Fig. 3B, upper panels). In lungs from non-COVID subjects that were not affected by respiratory disease (nc1, 8 and 11), NLRP3 (Fig. 3A, lower panels) and caspase-1 expressions were significantly lower (Figs. 3A, B: lower panels and Fig. 3C). However, in lungs of 
subjects, that were affected by ARDS, NLRP3 and caspase1 expression was not significantly different from COVID-19 lungs (Fig. 3D).

\section{Discussion}

COVID-19 has been described largely as a respiratory disease; indeed, the respiratory tract and alveolus are amongst the primary sites of infection. However, it is also an inflammatory disease where release of inflammatory cytokines is the cause of organ injury and damage. The endothelium is the converging site of the inflammation as its activation (expression of adhesion molecules and cytokines) leads to immune cell recruitment; thus it is reasonable to conclude that COVID-19 is potentially a vascular disease $[11,28,29]$. While this would be an indirect impact of the virus, more recent studies also provide evidence of a direct effect i.e. infection by SARS-CoV-2 virus of endothelial cells [30]. Our inspection of autopsies of the 8 COVID-19 patients showed macro and microthrombi in almost all fields imaged, indicating coagulation pathology. This was not observed in autopsies of non-COVID-19 lung sections. As is well established, coagulation is closely linked to endothelial inflammation signaling; inflammatory moieties on the endothelium increase leukocyte infiltration and alter coagulation control driving a procoagulant direction [31]. Thus, COVID-19 which is increasingly being described as a vascular disease should perhaps be more accurately defined as a pathology which has its origins in "endothelial inflammation" signaling.

Inflammasome activation on the endothelium plays a major part in cell death and injury with inflammation. The NLRP3 inflammasome is a multiprotein complex comprised of three basic components: (1) A sensor such as a NOD-like receptor (NLR) (2) the adaptor protein apoptosis-associated speck-like protein containing a caspase-recruitment domain (ASC) and (3) the inflammatory cysteine aspartase caspase-1. The assembly of this complex leads to release of caspase- 1 which then exerts its catalytic activity on the pro-inflammatory cytokines (IL-1 $\beta$ ) that after their release perpetuate cell death, specifically inflammation induced cell death or pyroptosis $[17,18]$.

A recent report showed high levels of NLRP3 inflammasome and caspase-1 in patients with fatal COVID [20]. This is not surprising as increased NLRP3 is associated with various inflammatory lung pathologies including acute lung injury and ARDS $[32,33]$. The COVID-19 lung autopsies in this study, showed NLRP3 expression throughout the lung, but intense expression was seen along the lung vessel walls implying inflammasome expression on the endothelium. The downstream effector of NLRP3 inflammasome activation, Caspase-1 was found to be expressed throughout the lungs including in the vascular structures. Caspase-1 is considered as a key pyroptotic mediator; it reportedly drives pulmonary vascular endothelial cell death [17]. Elsewhere too, high caspase-1 expression has been reported with both COVID-19 [20] and with other lung inflammatory pathologies [34]; however its expression on the endothelium or vascular wall with COVID-19 has not been documented. Possibly the NLRP3-caspase-1 axis can directly (via caspase-1 driven pyroptosis) or indirectly (via NLRP3 driven chemotactic immune cell recruitment [35]) injure the endothelial layer. This confluence of vascular injury, thrombosis and dysregulated inflammation seems to propagate lung damage with COVID-19 and supports a pivotal role for the pulmonary endothelium in severe and fatal COVID-19. In contrast, non-COVID-19 lungs of subjects that did not have respiratory disease, had significantly lower expression of NLRP3 and caspase-1, indicating that an engagement of the NLRP3 pathway in COVID-19 and in ARDS.

As NLRP3 inflammasome driven pyroptosis is being considered to play a leading role in the pathogenesis of multi-organ failure with COVID-19 [36], there is some speculation on the mechanisms by which inflammasome activation occurs upon SARS-CoV-2 infection. One possibility is that the SARS-CoV-2 spike protein's binding to cell surface-expressed angiotensin-converting enzyme 2 (ACE2) directly triggers its enzymatic activation and alters membrane polarity that can result in activation of NLPR3 inflammasome [37]. Or NLRP3 could be activated via Angiotensin II which is reported to facilitate the assembly of the inflammasome. A third possibility could be via interaction of damage associated molecular patterns (DAMPs that are released post infection) and members of the complement cascade with the SARS-CoV-2 virus. Potent cleavage fragments of DAMPs and complement cascade can potentially activate the inflammasome [38]. Yet another possibility is that the stretch from ventilation activates the inflammasome [39]. Once activated around the vascular wall (endothelial layer), the NLRP3 inflammasome would lead to release of caspase-1 and interleukin-1 $\beta$ that would facilitate pyroptosis (cell death) of the endothelium (Schema 1). 
To the best of our knowledge, this is the first study on NLRP3 expression in the vascular structures in lungs of fatal cases of COVID-19. The origin of several events that exacerbate inflammation and injury with COVID-19 (such as immune cell aggregation and extravasation, edema, formation of thrombi and leukopenia) possibly lies in pulmonary endothelial inflammasome activation and pyroptotic cell death. Therefore, NLRP3 inhibitors have been suggested for as a potential treatment strategy and are currently being explored for management of moderate COVID-19 symptoms (NCT04540120) [19, 40].

A major drawback of this study is that our sample size is small. Moreover, paraffin based post-mortem samples offer a snapshot of the disease and cannot recreate the evolving disease process. Histology is also impacted with the effects of clinical care and treatment as comorbidities, ventilation and medication pose as challenges in interpretation of results. Nevertheless, this study identifies endothelial NLRP3 inflammation, and documents thrombi and altered vascular structures in the lungs of fatal COVID-19 patients.

\section{Conclusions}

Taken together, our data show that in COVID-19 affected subjects, lungs show inflammasome formation in the specifically along the vessel wall. This indicates a role for NLRP3 inflammasome pathway in amplification of inflammation post SARS-CoV2 infection and a potential usage of antagonists or blockers of the NLRP3 pathway in COVID-19 inflammation regulation and control. Overall, this report adds to the growing list of studies on COVID-19 associated pulmonary pathology that highlight the importance of vascular endothelial inflammation in progression to severe and fatal disease.

\section{Abbreviations}

ACE2: Angiotensin-converting enzyme 2

ARDS: Acute Respiratory Distress Syndrome

ASC: Apoptosis-associated speck-like protein containing a caspase-recruitment domain

COVID-19: Coronavirus disease of 2019.

H \& E: Hematoxylin and Eosin

NLRP3: NOD-like receptor protein 3

SARS-CoV-2: Severe Acute Respiratory Syndrome Coronavirus

\section{Declarations}

Ethics approval and consent: Written informed consent was obtained for postmortem examination from the next of kin of these patients. Ethics approval and consent was obtained.

Consent for publication: Not applicable

Availability of data and materials: The samples, datasets and analysis of this study are available from the corresponding author on reasonable request.

Competing Interests: The authors declare that they have no competing interests.

Sources of Funding: This research was supported by NIH R56 HL139559.

Authors' Contributions: OP and JQT carried out the immunostaining experiments. OP made the figures and helped in drafting the manuscript. EW carried out the quantitation studies. Post mortem lung H\&E was done by LL, MF and KM. CR and CM 
provided assistance is study design. Overall concept, study design, interpretation of data and writing of the manuscript was done by SC. All authors approved the final manuscript.

\section{References}

1. Xie J, Tong Z, Guan X, Du B, Qiu H: Clinical Characteristics of Patients Who Died of Coronavirus Disease 2019 in China.JAMA network open 2020, 3:e205619.

2. Guan WJ, Ni ZY, Hu Y, Liang WH, Ou CQ, He JX, Liu L, Shan H, Lei CL, Hui DSC, et al: Clinical Characteristics of Coronavirus Disease 2019 in China. The New England journal of medicine 2020, 382:1708-1720.

3. Fox SE, Akmatbekov A, Harbert JL, Li G, Quincy Brown J, Vander Heide RS: Pulmonary and cardiac pathology in African American patients with COVID-19: an autopsy series from New Orleans. The Lancet Respiratory medicine 2020, 8:681-686.

4. Jin Y, Yang H, Ji W, Wu W, Chen S, Zhang W, Duan G: Virology, Epidemiology, Pathogenesis, and Control of COVID19. Viruses 2020, 12.

5. Gustine JN, Jones D: Immunopathology of Hyperinflammation in COVID-19. The American journal of pathology 2021, 191:4-17.

6. Carsana L, Sonzogni A, Nasr A, Rossi RS, Pellegrinelli A, Zerbi P, Rech R, Colombo R, Antinori S, Corbellino M, et al: Pulmonary post-mortem findings in a series of COVID-19 cases from northern Italy: a two-centre descriptive study. The Lancet Infectious diseases 2020, 20:1135-1140.

7. Varga Z, Flammer AJ, Steiger P, Haberecker M, Andermatt R, Zinkernagel AS, Mehra MR, Schuepbach RA, Ruschitzka F, Moch H: Endothelial cell infection and endotheliitis in COVID-19.Lancet 2020, 395:1417-1418.

8. Xu Z, Shi L, Wang Y, Zhang J, Huang L, Zhang C, Liu S, Zhao P, Liu H, Zhu L, et al: Pathological findings of COVID-19 associated with acute respiratory distress syndrome. The Lancet Respiratory medicine 2020, 8:420-422.

9. Haberman R, Axelrad J, Chen A, Castillo R, Yan D, Izmirly P, Neimann A, Adhikari S, Hudesman D, Scher JU: Covid-19 in Immune-Mediated Inflammatory Diseases - Case Series from New York. The New England journal of medicine 2020, 383:8588.

10. Del Valle DM, Kim-Schulze S, Huang HH, Beckmann ND, Nirenberg S, Wang B, Lavin Y, Swartz TH, Madduri D, Stock A, et al: An inflammatory cytokine signature predicts COVID-19 severity and survival.Nature medicine 2020, 26:1636-1643.

11. Ackermann M, Verleden SE, Kuehnel M, Haverich A, Welte T, Laenger F, Vanstapel A, Werlein C, Stark H, Tzankov A, et al: Pulmonary Vascular Endothelialitis, Thrombosis, and Angiogenesis in Covid-19. The New England journal of medicine 2020, 383:120-128.

12. Toews GB: Cytokines and the lung. The European respiratory journal Supplement 2001, 34:3s-17s.

13. Raman KS, Matsubara JA: Dysregulation of the NLRP3 Inflammasome in Diabetic Retinopathy and Potential Therapeutic Targets.Ocular immunology and inflammation 2020:1-9.

14. Wang Z, Zhang S, Xiao Y, Zhang W, Wu S, Qin T, Yue Y, Qian W, Li L: NLRP3 Inflammasome and Inflammatory Diseases. Oxidative medicine and cellular longevity 2020, 2020:4063562.

15. Anand PK, Malireddi RK, Kanneganti TD: Role of the nlrp3 inflammasome in microbial infection.Frontiers in microbiology 2011, 2:12.

16. Sha W, Mitoma H, Hanabuchi S, Bao M, Weng L, Sugimoto N, Liu Y, Zhang Z, Zhong J, Sun B, Liu YJ: Human NLRP3 inflammasome senses multiple types of bacterial RNAs. Proceedings of the National Academy of Sciences of the United States of America 2014, 111:16059-16064.

17. Singla S, Machado RF: Death of the Endothelium in Sepsis: Understanding the Crime Scene.American journal of respiratory cell and molecular biology 2018, 59:3-4.

18. Bergsbaken T, Fink SL, Cookson BT: Pyroptosis: host cell death and inflammation.Nature reviews Microbiology 2009, 7:99109.

19. Rodrigues TS, de Sa KSG, Ishimoto AY, Becerra A, Oliveira S, Almeida L, Goncalves AV, Perucello DB, Andrade WA, Castro R, et al: Inflammasomes are activated in response to SARS-CoV-2 infection and are associated with COVID-19 severity in 
patients. The Journal of experimental medicine 2021, 218.

20. Toldo S, Bussani R, Nuzzi V, Bonaventura A, Mauro AG, Cannata A, Pillappa R, Sinagra G, Nana-Sinkam P, Sime P, Abbate A: Inflammasome formation in the lungs of patients with fatal COVID-19.Inflammation research : official journal of the European Histamine Research Society [et al] 2021, 70:7-10.

21. Schurink B, Roos E, Radonic T, Barbe E, Bouman CSC, de Boer HH, de Bree GJ, Bulle EB, Aronica EM, Florquin S, et al: Viral presence and immunopathology in patients with lethal COVID-19: a prospective autopsy cohort study. The Lancet Microbe 2020, 1:e290-e299.

22. Bradley BT, Maioli H, Johnston R, Chaudhry I, Fink SL, Xu H, Najafian B, Deutsch G, Lacy JM, Williams T, et al: Histopathology and ultrastructural findings of fatal COVID-19 infections in Washington State: a case series.Lancet 2020, 396:320-332.

23. Hanley B, Naresh KN, Roufosse C, Nicholson AG, Weir J, Cooke GS, Thursz M, Manousou P, Corbett R, Goldin R, et al: Histopathological findings and viral tropism in UK patients with severe fatal COVID-19: a post-mortem study. The Lancet Microbe 2020, 1:e245-e253.

24. Nagashima S, Mendes MC, Camargo Martins AP, Borges NH, Godoy TM, Miggiolaro A, da Silva Deziderio F, Machado-Souza C, de Noronha L: Endothelial Dysfunction and Thrombosis in Patients With COVID-19-Brief Report.Arteriosclerosis, thrombosis, and vascular biology 2020, 40:2404-2407.

25. Browning E, Wang H, Hong N, Yu K, Buerk DG, DeBolt K, Gonder D, Sorokina EM, Patel P, De Leon DD, et al: Mechanotransduction drives post ischemic revascularization through K(ATP) channel closure and production of reactive oxygen species.Antioxid Redox Signal 2014, 20:872-886.

26. Tao JQ, Sorokina EM, Vazquez Medina JP, Mishra MK, Yamada Y, Satalin J, Nieman GF, Nellen JR, Beduhn B, Cantu E, et al: Onset of Inflammation With Ischemia: Implications for Donor Lung Preservation and Transplant Survival.American journal of transplantation : official journal of the American Society of Transplantation and the American Society of Transplant Surgeons 2016, 16:2598-2611.

27. Chatterjee S, Tao JQ, Johncola A, Guo W, Caporale A, Langham MC, Wehrli FW: Acute exposure to e-cigarettes causes inflammation and pulmonary endothelial oxidative stress in nonsmoking, healthy young subjects.American journal of physiology Lung cellular and molecular physiology 2019, 317:L155-L166.

28. Evans PC, Rainger GE, Mason JC, Guzik TJ, Osto E, Stamataki Z, Neil D, Hoefer IE, Fragiadaki M, Waltenberger J, et al: Endothelial dysfunction in COVID-19: a position paper of the ESC Working Group for Atherosclerosis and Vascular Biology, and the ESC Council of Basic Cardiovascular Science. Cardiovascular research 2020, 116:2177-2184.

29. Kumar A, Narayan RK, Kumari C, Faiq MA, Kulandhasamy M, Kant K, Pareek V: SARS-CoV-2 cell entry receptor ACE2 mediated endothelial dysfunction leads to vascular thrombosis in COVID-19 patients.Medical hypotheses 2020, 145:110320.

30. Nascimento Conde J, Schutt WR, Gorbunova EE, Mackow ER: Recombinant ACE2 Expression Is Required for SARS-CoV-2 To Infect Primary Human Endothelial Cells and Induce Inflammatory and Procoagulative Responses.mBio 2020, 11.

31. van Hinsbergh VW: Endothelium-role in regulation of coagulation and inflammation.Seminars in immunopathology 2012, 34:93-106.

32. Jones HD, Crother TR, Gonzalez-Villalobos RA, Jupelli M, Chen S, Dagvadorj J, Arditi M, Shimada K: The NLRP3 inflammasome is required for the development of hypoxemia in LPS/mechanical ventilation acute lung injury.American journal of respiratory cell and molecular biology 2014, 50:270-280.

33. Grailer JJ, Canning BA, Kalbitz M, Haggadone MD, Dhond RM, Andjelkovic AV, Zetoune FS, Ward PA: Critical role for the NLRP3 inflammasome during acute lung injury.Journal of immunology 2014, 192:5974-5983.

34. Simpson JL, Phipps S, Baines KJ, Oreo KM, Gunawardhana L, Gibson PG: Elevated expression of the NLRP3 inflammasome in neutrophilic asthma. The European respiratory journal 2014, 43:1067-1076.

35. Inoue M, Williams KL, Gunn MD, Shinohara ML: NLRP3 inflammasome induces chemotactic immune cell migration to the CNS in experimental autoimmune encephalomyelitis. Proceedings of the National Academy of Sciences of the United States of America 2012, 109:10480-10485. 
36. Lee C, Choi WJ: Overview of COVID-19 inflammatory pathogenesis from the therapeutic perspective.Archives of pharmacal research 2021, 44:99-116.

37. Jha A, Kumar V, Haque S, Ayasolla K, Saha S, Lan X, Malhotra A, Saleem MA, Skorecki K, Singhal PC: Alterations in plasma membrane ion channel structures stimulate NLRP3 inflammasome activation in APOL1 risk milieu. The FEBS journal 2020, 287:2000-2022.

38. Ratajczak MZ, Kucia M: SARS-CoV-2 infection and overactivation of NIrp3 inflammasome as a trigger of cytokine "storm" and risk factor for damage of hematopoietic stem cells.Leukemia 2020, 34:1726-1729.

39. Wu J, Yan Z, Schwartz DE, Yu J, Malik AB, Hu G: Activation of NLRP3 inflammasome in alveolar macrophages contributes to mechanical stretch-induced lung inflammation and injury.Journal of immunology 2013, 190:3590-3599.

40. Freeman TL, Swartz TH: Targeting the NLRP3 Inflammasome in Severe COVID-19.Frontiers in immunology 2020, 11:1518.

\section{Figures}

Figure $1 \mathrm{~A}$.
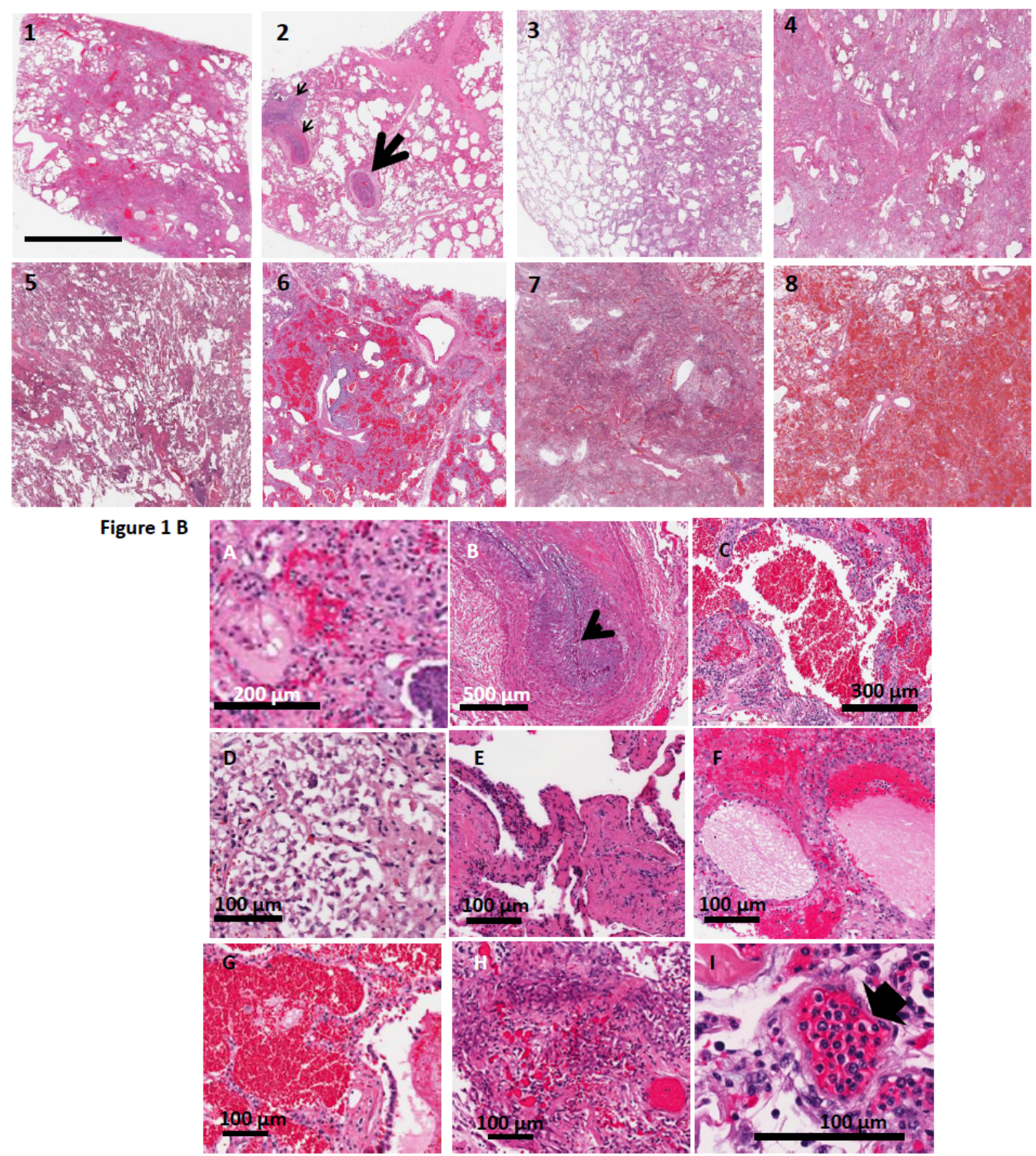

Figure 1 
Hematoxylin and Eosin-stained sections staining from representative regions of the lung parenchyma of post-mortem lung tissue of 8 COVID-19 patients. A. All patients show extensive alteration of lung microstructure in the form of alveolar damage, fibrin exudation into alveolar space, thrombi and fibroblastic proliferation. The septa are thickened and there is presence of hyaline membranes and dense infiltrates. Scale bar is $3 \mathrm{~mm}$. 1: Alveolar damage with collagen deposition and exudative pattern of damage 2. Large thrombi and smaller caliber arteries showing fibrin thrombi (arrows) 3. Alveolar damage pattern arising from fibroblastic proliferations 4 and 5. Exudate in the entire lung 6. Necrosis with blood and exudate in the lung parenchyma 7. Hemorrhagic infarction of lung tissue adjacent to a pulmonary artery with thrombotic material 8 . Pulmonary hemorrhage with blood and fibrin exudation into the parenchyma B. $\mathrm{H}$ and E staining at higher magnification: All patients had extensive diffuse alveolar damage, microthrombi and edema in regions of the lung. A. Fibroblastic proliferation B. Plugged airway due to remodeling $C$. Coagulation necrosis with blood in the lung tissue D. Proliferative phase of diffuse alveolar damage E. Patchy distribution of damage F. Proteinaceous exudates in alveolar spaces G. Blood and fibrin exudation into parenchyma $\mathrm{H}$ : Fibroblastic proliferation I: Endotheliitis of small vessel $<100 \mu \mathrm{m}$ with infiltration of the vessel wall by lymphocytes (arrow shows infiltrated cells) C. (unavailable with this version):Thrombi and microthrombi were identified in 7 of the 8 patients. Images of vessels were chosen to emphasize the microthombi. Box is magnified in the right panel. Arrow shows microthombi on alveolar septa.
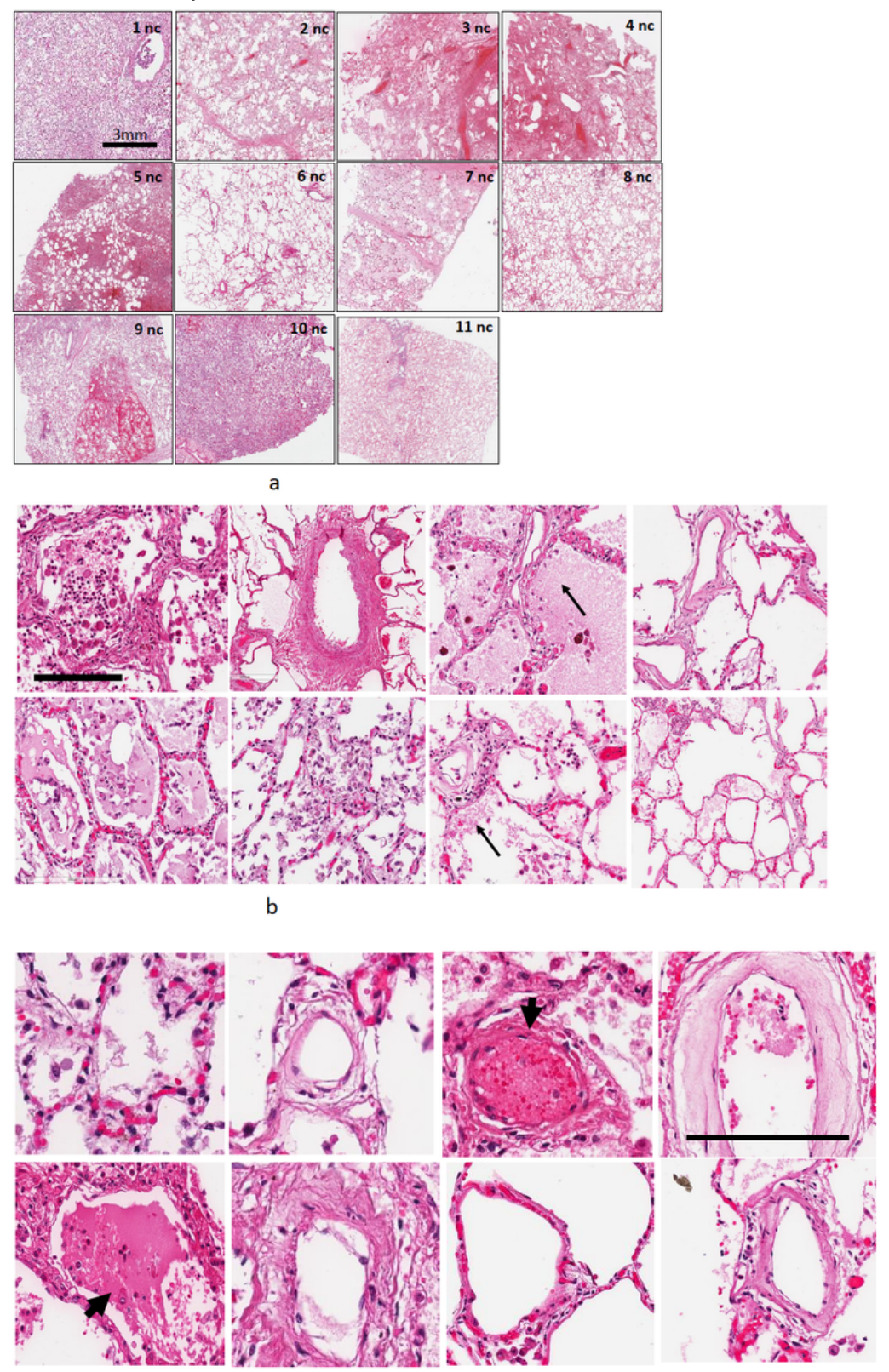
Figure 2

A. Hematoxylin and Eosin-stained sections staining from representative regions of the lung parenchyma of post-mortem lung tissue of 11 non COVID-19 patients. Scale bar is $3 \mathrm{~mm}$. B. H and E staining at higher magnification: All patients had diffuse alveolar damage, microthrombi and edema in regions of the lung. Arrows show proteinaceous exudate in the airspaces. Scale bar is 200 microns C. Vascular structures in lungs from non-COVID-19 sources. Arrows show thrombi in vessels. About $40 \%$ of the fields showed thrombi. Scale bar is 100 microns.
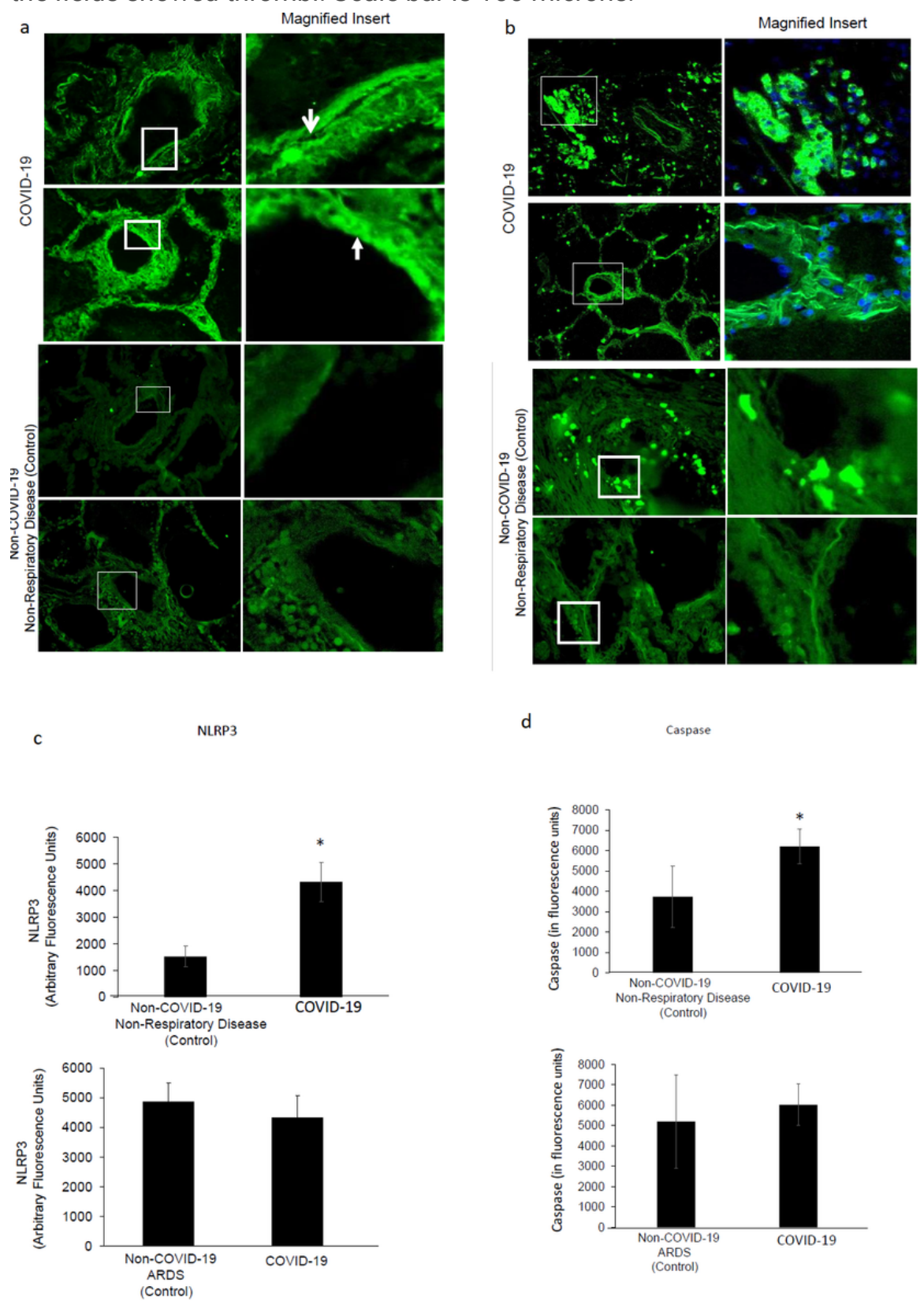

\section{Figure 3}

Inflammasome in the lungs of patients with COVID-19 infection. Representative images of the immunofluorescence in lung sections stained with anti-NLRP3 and Caspase-1. A. The NLRP3 subunit (green) was visualized along the walls of arterioles (arrow). Upper panels: COVID-19 lungs. Lower Panels: Lungs from non-COVID 19 subjects, without respiratory disease. B. Caspase staining (green). Upper panels: COVID-19 lungs. Lower Panels: Lungs from non-COVID 19 subjects, without respiratory disease. $C$ and D. Quantitation of the fluorescence Intensity of the images using MetaMorph Imaging Program. ${ }^{*} p<0.01$ as compared to non-COVID lungs. 


\section{Sars Cov-2}

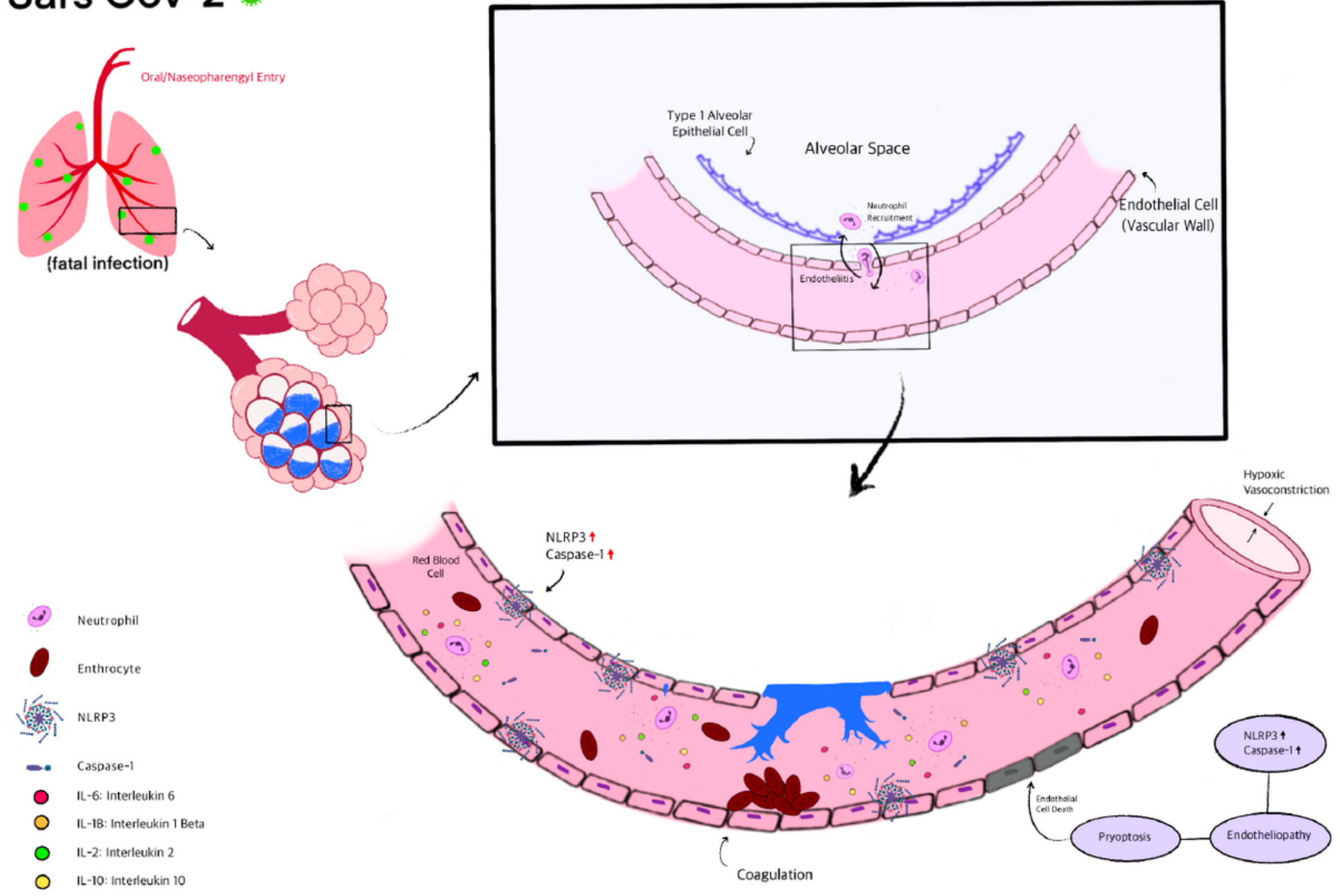

Figure 4

Overview of SARS-CoV-2 entry, infection and endothelial inflammation and cell death. As is well established, oral nasopharyngeal entry of SARS-CoV-2 is followed by its binding to the alveolar epithelium. The infected pneumocytes secrete cytokine and chemokines, which attract neutrophils to the alveolar space, leading to a possible breach of the alveolar wall. Meanwhile, endothelial cells overexpress NLRP3 as we observed in the autopsies (either by infection, or via increased amounts of chemokines and cytokines). The NLRP3 pathway drives endothelial pyroptosis. The leads to breakdown of the endothelialalveolar barrier and causes interstitial and alveolar space flooding. Endothelial cell death and debris activates coagulation cascades that promotes thrombi formation. 